\title{
Erratum to "miR319, miR390, and miR393 Are Involved in Aluminum Response in Flax (Linum usitatissimum L.)"
}

\author{
Alexey A. Dmitriev, ${ }^{1}$ Anna V. Kudryavtseva, ${ }^{1}$ Nadezhda L. Bolsheva, ${ }^{1}$ \\ Alexander V. Zyablitsin, ${ }^{1}$ Tatiana A. Rozhmina, ${ }^{1,2}$ Natalya V. Kishlyan, \\ George S. Krasnov, ${ }^{1}$ Anna S. Speranskaya, ${ }^{1,3}$ Anastasia A. Krinitsina, ${ }^{3}$ \\ Asiya F. Sadritdinova, ${ }^{1}$ Anastasiya V. Snezhkina, ${ }^{1}$ \\ Maria S. Fedorova, ${ }^{1}$ Olga Yu. Yurkevich, ${ }^{1}$ Olga V. Muravenko, ${ }^{1}$ \\ Maxim S. Belenikin, ${ }^{1,3}$ and Nataliya V. Melnikova ${ }^{1}$ \\ ${ }^{1}$ Engelhardt Institute of Molecular Biology, Russian Academy of Sciences, Moscow 119991, Russia \\ ${ }^{2}$ All-Russian Research Institute for Flax, Torzhok 172002, Russia \\ ${ }^{3}$ Faculty of Biology, Lomonosov Moscow State University, Moscow 119991, Russia \\ Correspondence should be addressed to Nataliya V. Melnikova; mnv-4529264@yandex.ru
}

Received 21 May 2017; Accepted 30 May 2017; Published 13 August 2017

Copyright $\odot 2017$ Alexey A. Dmitriev et al. This is an open access article distributed under the Creative Commons Attribution License, which permits unrestricted use, distribution, and reproduction in any medium, provided the original work is properly cited.

In the article titled "miR319, miR390, and miR393 Are Involved in Aluminum Response in Flax (Linum usitatissimum L.)" [1], incorrect versions of Supplementary Table 2 "MicroRNA expression" and Supplementary Table 3 "MicroRNA targets" were published. The correct supplementary materials are available here.

\section{References}

[1] A. A. Dmitriev, A. V. Kudryavtseva, N. L. Bolsheva et al., "miR319, miR390, and miR393 Are Involved in Aluminum Response in Flax (Linum usitatissimum L.)," BioMed Research International, vol. 2017, Article ID 4975146, 6 pages, 2017. 

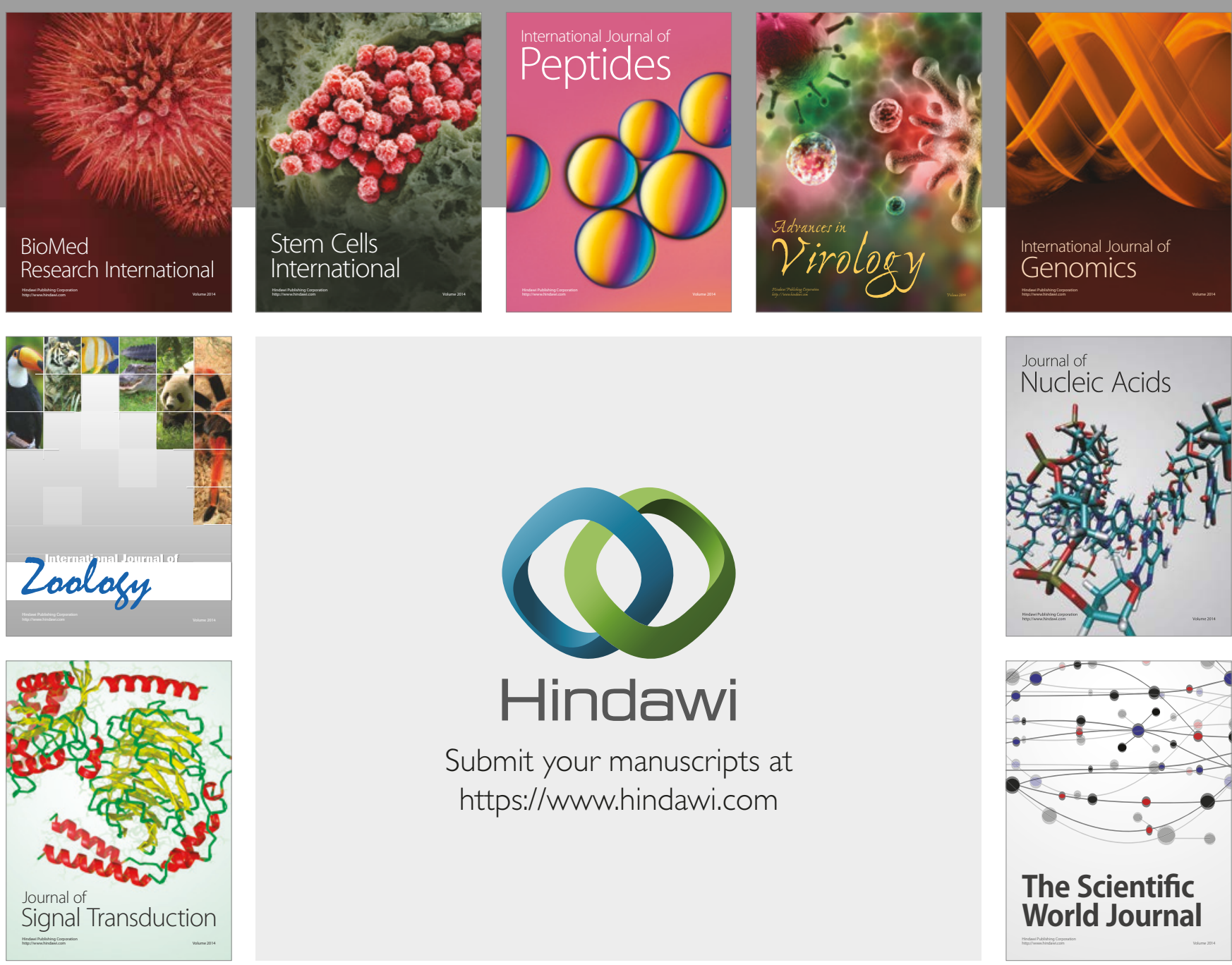

Submit your manuscripts at

https://www.hindawi.com
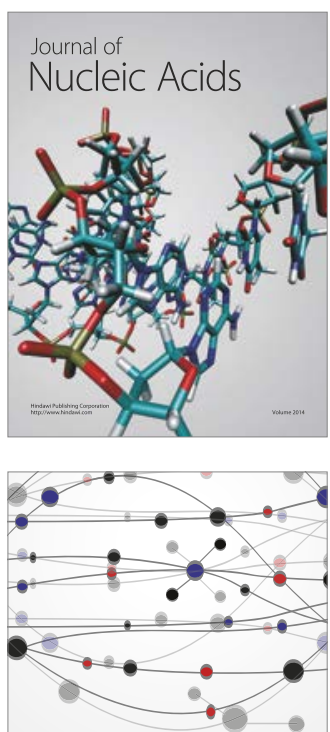

The Scientific World Journal

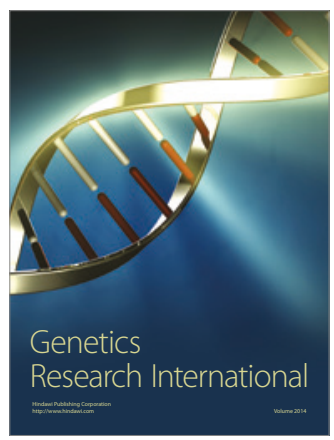

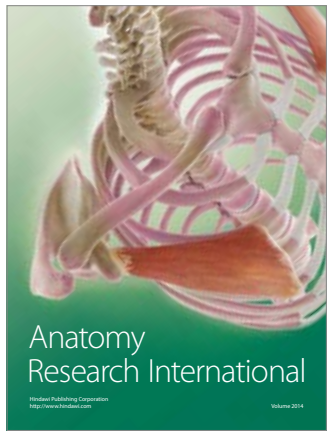

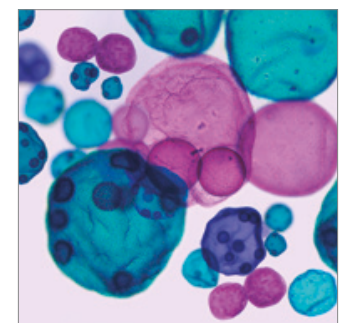

International Journal of Microbiology
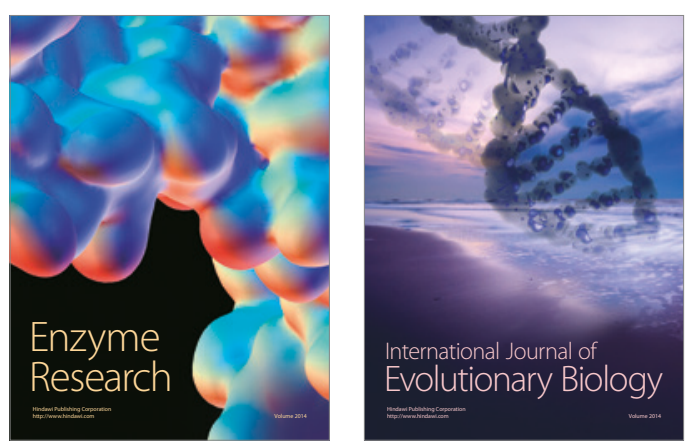
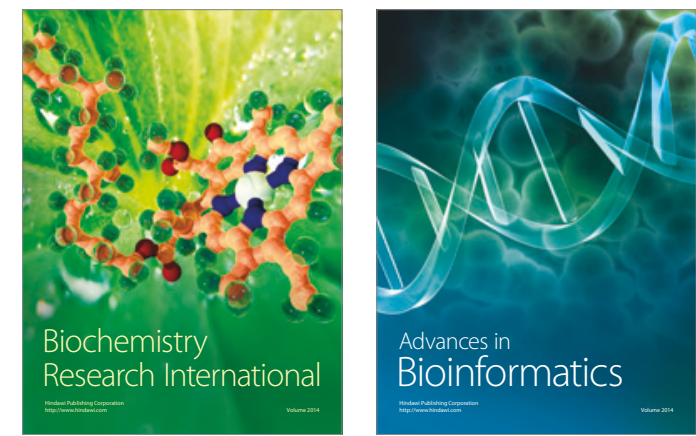

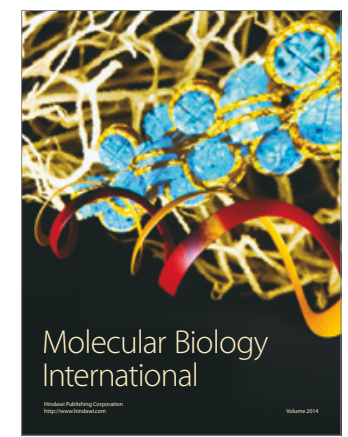

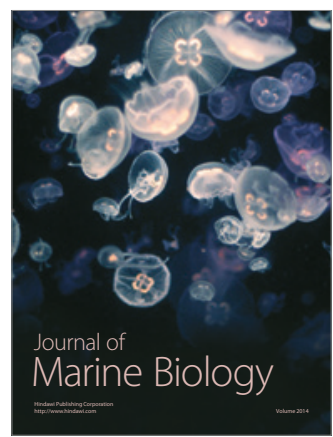

